\title{
Degradation of Dyestuff Pollutant Sudan I Using Advanced Oxidation Process
}

\author{
Pramod Gopinathan Nair ${ }^{*}$, Swathy Vijayakumar', Teena Lisluke², \\ Menacheri Sunil Paul Mathew ${ }^{3}$, Charuvila Thankappan Aravindakumar ${ }^{3}$ \\ ${ }^{1}$ Department of Chemistry, NSS Hindu College, Changanassery, India \\ ${ }^{2}$ Department of Chemistry, Christian College, Chenganoor, India \\ ${ }^{3}$ School of Environmental Sciences, Mahatma Gandhi University, Kottayam, India \\ Email: ${ }^{*}$ pramodmgu09@gmail.com
}

Received 2 July 2014; revised 26 July 2014; accepted 21 August 2014

Copyright (C) 2014 by authors and Scientific Research Publishing Inc.

This work is licensed under the Creative Commons Attribution International License (CC BY).

http://creativecommons.org/licenses/by/4.0/

c) (i) Open Access

\section{Abstract}

Due to an increasing environmental pollution, a search for the cost effective treatment and disposal of the dyes from the textile effluents is getting more and more importance. Oxidation and reduction processes play important roles in the degradation treatments of the azo dyes. The latter process is more effective and in consequence its mechanism is also better understood. The mechanism of the oxidation processes, the intermediates involved in these reactions and their role in the effectiveness of the oxidative degradation of the azo dyes, viz, phenyl azo $\beta$-naphthol (PAN), Sudan I. On exposure to sunlight at $21 / 2$ hours for various samples in different concentrations of PAN mixed with Fenton reagent, when the reactive intermediate reacted with the colour, the pH $v s$. absorbance generally showed significant degradation in between pH 5 and 6 . The results were compared with the same samples on exposure to uv-light of $254 \mathrm{~nm}$ and irradiated at 20 minutes. The degradation occurred in samples of relatively high concentrations, viz, $10^{-3}$ and $5 \times 10^{-4} \mathrm{~mol}$. $\mathrm{dm}^{-3}$ at near neutral $\mathrm{pH} 6$ whereas. Low concentration samples such as $10^{-4}$ and $5 \times 10^{-5} \mathrm{~mol}^{-\mathrm{dm}^{-3}}$ showed degradation towards more acidic range of $\mathrm{pH} 2$ to 4 . In advanced oxidation process (AOP), generally reactive, strongly oxidizing ${ }^{\circ} \mathrm{OH}$ radicals play a main role in destruction of the dye molecules. The proposed mechanisms and the rate coefficients for the reactions of ${ }^{\circ} \mathrm{OH}$ intermediates with the dye molecules and with model compounds are summarized.

\section{Keywords}

Azo Dyes, Degradation, Advanced Oxidation Process, Textile Effluent, Phenyl Azo $\beta$-Naphthol

\footnotetext{
${ }^{*}$ Corresponding author.
} 


\section{Introduction}

Azo types of dyes [1], characterized by having an azogroups consisting of two nitrogen atoms $(-\mathrm{N}=\mathrm{N}-)$ as the chromophore in the molecule. Because of their toxicity and potentially carcinogenic nature, waste waters originating from dyes production and application industries pose a major threat to the surrounding ecosystem and human health. It is known that azodyes are largely non-biodegradable in aerobic conditions due to the strong electron withdrawing character of the azogroup [2], while in anaerobic conditions [3]; they can be reduced to more hazardous intermediates, such as aromatic amines. Other common commercial processes, such as coagulation/fluoccation and adsorption, do not involve chemical transformations and generally transfer waste components from one phase to another, thus causing secondary loading environment [4].

Azodyes [5] are an important class of synthetic organic compounds used as colouring agents in the textile, paint, ink and plastic industries. Large amounts of these dyes remain in the effect after the completion of the dyeing process. Consequently, very small amount of dyes in waste water is highly visible. A side from their negative aesthetic effects, certain azodyes and their biotransformation products has been shown to be toxic [6] to aquatic life and mutagenic to humans. Azodyes are stable compounds, difficult to destroy or to be decomposed by common treatment in a biological treating station. Azodyes may be decolorized by cleavage of the azobond, to which the color is associated. The reactive dyes are widely used in the textile industries because of its simple dyeing procedure and good stability during washing process. The textile processing industry is putting a severe burden on the environment through the release of heavily polluted wastewaters. The presence of these dyes in the aqueous ecosystems is the cause of serious environmental and health concerns. Several methods are used to treat textile effluents to achieve decolourization.

Azodyes occupy the leading place in the total volume of commercially produced synthetic dyes and are widely used in various branches of industry. On the one hand, azodye should be resistant to various oxidants (e.g. under laundering conditions) and on the other hand, their degradation in industrial waste water treatment is an urgent problem. Due to the presence of stable chromophoric azogroups $(-\mathrm{N}=\mathrm{N}-)$, electron withdrawing and electron donating groups [2], the dyes can be designed to resist chemical or photochemical degradation processes.

The disappearance of the dye is generally followed by spectrophotometry at the absorbance maximum between 450 and $600 \mathrm{~nm}$. Advanced Oxidation Process (AOP) [7] have been proposed and employed for the treatment of hazardous materials in waste water since 1990s. In principle, AOPs are based in the generation of hydroxyl radicals in water; it is highly reactive oxidant, [4] [8] which can oxidize organic compounds, especially unsaturated organic compounds. Among the most promising AOPs for water contaminated by organic molecules, [9] application of the Fenton's reagent (an aqueous mixture of $\mathrm{Fe}^{2+}$ and $\mathrm{H}_{2} \mathrm{O}_{2}$ that produce ${ }^{\circ} \mathrm{OH}$ radical) [10] [11] stands out due to its high oxidation power, rapid oxidation kinetics, being relatively inexpensive and easy to operate and maintain. However, the application of Fenton's reagent [12] in the destruction of organic pollutants is limited by the slurry system, because it produces a significant amount of Fe(III)-iron sludge, which requires further separation and disposal.

The expansion of worldwide textile industry has led to an equivalent expansion in the use of such synthetic dyestuffs, and only one among such azo dye categories, is the selected phenyl azo $\beta$-naphthol \{PAN\} or Sudan I [7]. The application of Fenton reagent in cost-effective way is not yet tried in the case of strong azo dye, like Sudan I. Therefore, the present method offers low-cost and moderate source of generating hydroxyl radical, which is the prime oxidizing agent for the decolorization of the selected azo dye. At the same time it results in a rise in environmental pollution due to the contamination of wastewater with the dyestuffs [13] [14]. Therefore, the necessity of degrading it effectively and at the same time ensuring that no harm byproducts are produced, which may unless otherwise, a threat for the natural water resources!

The Ecological and Toxicological Association of the Dyestuffs Manufacturing Industry (ETAD) was inaugurated in 1974 with the goals of minimizing environmental damage, protecting users and consumers and cooperating with government and public concerns in relation to the toxicological impact of their products [15]-[17]. A survey carried out by ETAD showed that of a total of approximately 4000 dyes that had been tested, more than $90 \%$ showed lethal dose $\left(\mathrm{LD}_{50}\right)$ values above $2 \times 10^{3} \mathrm{mg} / \mathrm{kg}$, the most toxic being in the group of basic and direct diazo dyes [17] [18]. Thus it appears that exposure to azo dyes does not cause acute toxicity, but with respect to systemic bioavailability, inhalation and contact with the skin by azo dyes is of concern, due to the possible generation of carcinogenic aromatic amines [19]. 
The disappearance of the dye is generally followed by spectrophotometry at the absorbance maximum between 450 and $600 \mathrm{~nm}$. Advanced Oxidation Process (AOP) [7] [11] has been proposed and employed for the treatment of hazardous materials in waste water since 1990s. In principle, AOPs are based in the generation of hydroxyl radicals in water; it is highly reactive oxidant which can oxidize organic compounds, especially unsaturated organic compounds. Among the most promising AOPs for water contaminated by organic molecules, application of the Fenton's reagent $\left\{\right.$ an aqueous mixture of $\mathrm{Fe}^{2+}$ and $\mathrm{H}_{2} \mathrm{O}_{2}$ that produce ${ }^{\bullet} \mathrm{OH}$ radical [11] stands out due to its high oxidation power, rapid oxidation kinetics, being relatively inexpensive and easy to operate and maintain. The advantage of the Fenton reagent is that no energy input is necessary to activate hydrogen peroxide [20]. The role of Fenton reagent for the production of ${ }^{\bullet} \mathrm{OH}$ radical is shown in (Figure 1). Hence, the present work proposes the oxidative degradation of PAN using Fenton reagent in both sun light and uv-light.

\section{Material and Methods}

$5 \mathrm{ml}$ aniline was allowed to dissolve in a mixture of $16 \mathrm{ml}$ concentrated $\mathrm{HCl}$ and $20 \mathrm{ml}$ t-distilled water. This mixture was kept in ice cold temperature 0 to $5^{\circ} \mathrm{C}$ and mixed the solution of $4 \mathrm{~g} \mathrm{NaNO}_{3}$ in $15 \mathrm{ml}$ water with vigorous shaking and controlled the temperature below $5^{\circ} \mathrm{C}$. A solution of $5 \mathrm{~g} \mathrm{NaOH}$ in $50 \mathrm{ml}$ triply-distilled water in which $8 \mathrm{~g}$ of $\beta$-naphthol was dissolved and kept in ice cold temperature $0^{\circ} \mathrm{C}$ to $5^{\circ} \mathrm{C}$. Mixed the solution drop by drop with continuous stirring at least for half an hour by keeping the temperature constant $0^{\circ} \mathrm{C}$ to $5^{\circ} \mathrm{C}$. Filtered and washed with cold water, dried and recrystalized in ethyl alcohol or glacial acetic acid. The solid, which imparted scarlet-red color and this amorphous form, was used for the entire experimentation as phenyl azo $\beta$-naphthol (PAN) or (Sudan I).

PAN $\left(10^{-4} \mathrm{~mol} \cdot \mathrm{dm}^{-3}\right)$ was prepared in chloroform in which various concentrations of Fenton reagent [7] [10] (mixture of ferrous sulfate $\left\{10^{-3}, 5 \times 10^{-4}, 10^{-4}, 5 \times 10^{-5} \mathrm{~mol} \cdot \mathrm{dm}^{-3}\right\}$ and $\mathrm{H}_{2} \mathrm{O}_{2}\left\{10^{-2} \mathrm{~mol} \cdot \mathrm{dm}^{-3}\right\}$ ) were mixed and irradiated in sun light at four different time scales such as $\left(1,1 \frac{1}{2}, 2 \& 2 \frac{1}{2}\right)$ hours. The experiments were performed at varying $\mathrm{pH}(2,4,5,6 \& 7)$. Optical density of the sample at various concentrations of ferrous sulfate were observed using colorimeter (DR/890-portable colorimeter) in varying time. In order to find out the experiments in parallel way by replacing the sun light source as uv-lamp (wavelength $254 \mathrm{~nm}$ ) (Specrtonics 240 to 365) and irradiated the mixture in 20 minutes.

\section{Results and Discussion}

The effect of concentration of Fenton reagent on absorbance was studied using both irradiated source such as sunlight and uv-lamp of $254 \mathrm{~nm}$ for observing the decolourization efficiency of the substrate at near neutral $\mathrm{pH}$ 6. Figure 2 showed $50 \%$ reduction in an experimental duration of $2 \frac{1}{2}$ hours on exposure of sunlight in peek summer and Figure 3, a reduction in $42 \%$ observed in just 20 minutes on exposure of uv-light source at $254 \mathrm{~nm}$, simultaneously. The best discoloration is observed in between $(1-5) \times 10^{-4} \mathrm{~mol} \cdot \mathrm{dm}^{-3}$ in Figure 2 using sunlight and a range of concentrations $(2-3.7) \times 10^{-4} \mathrm{~mol} \cdot \mathrm{dm}^{-3}$ on exposure of uv-light shown in Figure 3 .

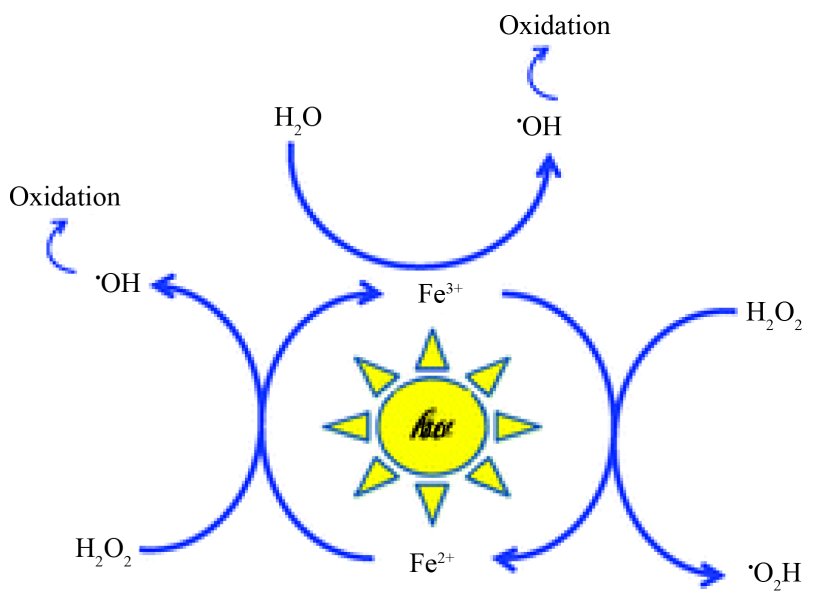

Figure 1. Schematic representations for the coupled Fenton's and photo-Fenton's reactions. 


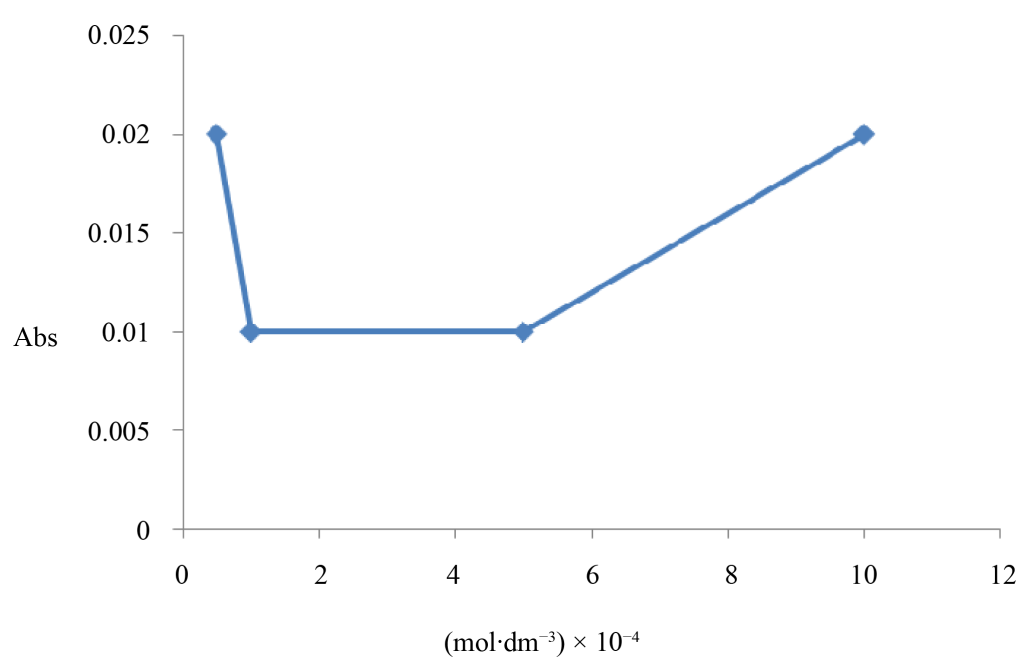

Figure 2. Effect of concentration on absorbance of PAN at pH 6 irradiated (2 1/2 hours) by sunlight.

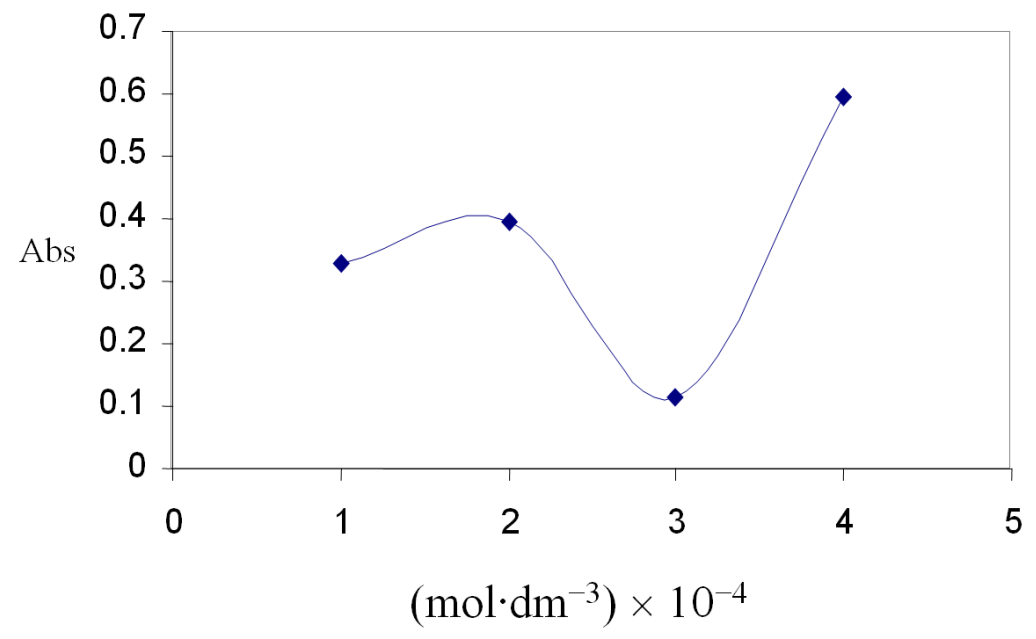

Figure 3. Effect of concentration of Fenton reagent on absorbance of PAN at pH 6 irradiated $20 \mathrm{~min}$ by $254 \mathrm{~nm}$ uv-light.

In addition to view of relatively low concentration of $\mathrm{Fe}^{2+}$ in this work, which seemed to be cost-effective, energy saver and environmental friendly, an earlier work reported that catalytic nature of iron [21] helps in enhancing the reaction occurring at lower concentration of iron in solar Fenton's process.

In Figure 3, discoloration observed maximum at $3 \times 10^{-4} \mathrm{~mol} \cdot \mathrm{dm}^{-3}$ on exposure to $254 \mathrm{~nm}$ uv-light. However, all concentations above $3 \times 10^{-4} \mathrm{~mol} \cdot \mathrm{dm}^{-3}$, a decrease in color removal was observed. This inhibitory effect at the higher Fenton concentrations could be explained by an observation (referring to the classical Fenton reaction) that in the absence of organic substrates, excessive ferrous ions (formed from $\mathrm{Fe}^{2+} / \mathrm{H}_{2} \mathrm{O}_{2}$ process) are the dominant hydroxyl radical's scavenger through the following reaction (3.1) [22] [23].

$$
\mathrm{Fe}^{2+}+{ }^{\cdot} \mathrm{OH} \rightarrow \mathrm{Fe}^{3+}+\mathrm{OH}^{-}
$$

The solution of PAN in chloroform mixed with Fenton reagent, under acidic conditions, iron compound release $\mathrm{Fe}^{2+}$ to the solution. It has been shown that the iron compound dissolves faster at lower $\mathrm{pH}$ than at high $\mathrm{pH}$ [23]. This remains in agreement with the fact, that the Fenton reaction is effective in acidic conditions. Then, $\mathrm{Fe}^{2+}$ will decompose $\mathrm{H}_{2} \mathrm{O}_{2}$ to generate hydroxyl radicals according to the Fenton reaction. The optimal $\mathrm{pH}$ in the range of (2 - 4) was reported to be a highly important factor for effective Fenton oxidation [24]-[26]. Hence, the effect of $\mathrm{pH}$ on colour removal estimated in between $\mathrm{pH}$ values varying from 2 - 4 shown in Figure 4. A decrease in the decolourization efficiency at $\mathrm{pH} 4$ indicating in accordance with another report that near $\mathrm{pH} 4$, 
rapid $\mathrm{H}_{2} \mathrm{O}_{2}$ decomposition, probably on the surface of the ferric hydroxide floc, would result a fall in the appreciable amount of hydroxyl radical production [27] [28].

\section{Structural Elucidation of PAN}

The structural elucidation and characterization of PAN were carried using NMR Spectrometer [Varian $600 \mathrm{MHz}$ IFC PFG] at Inter University Instrumentation Centre [IUIC], School of Environmental Sciences, Mahatma Gandhi University. The results observed in Figure 5, the peak at 1.596 is due to the presence of water in the

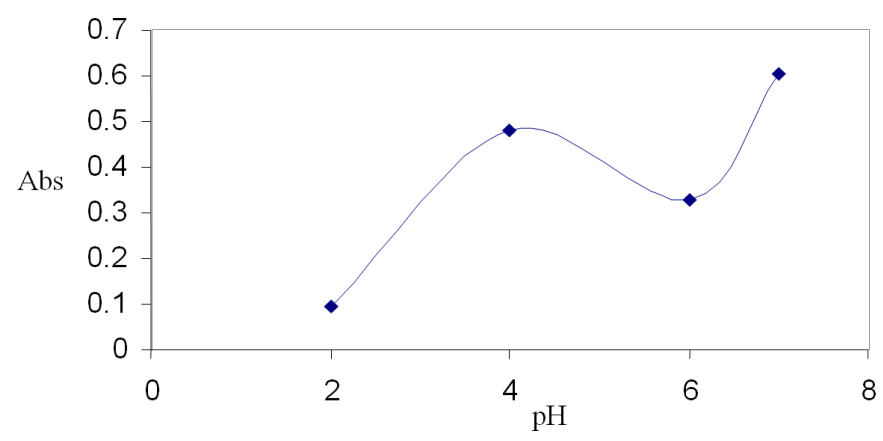

Figure 4. Effect of pH on absorbance of PAN $\left(10^{-3} \mathrm{~mol} \cdot \mathrm{dm}^{-3}\right)$ irradiated $20 \mathrm{~min}$ by $254 \mathrm{~nm}$ uv-light.

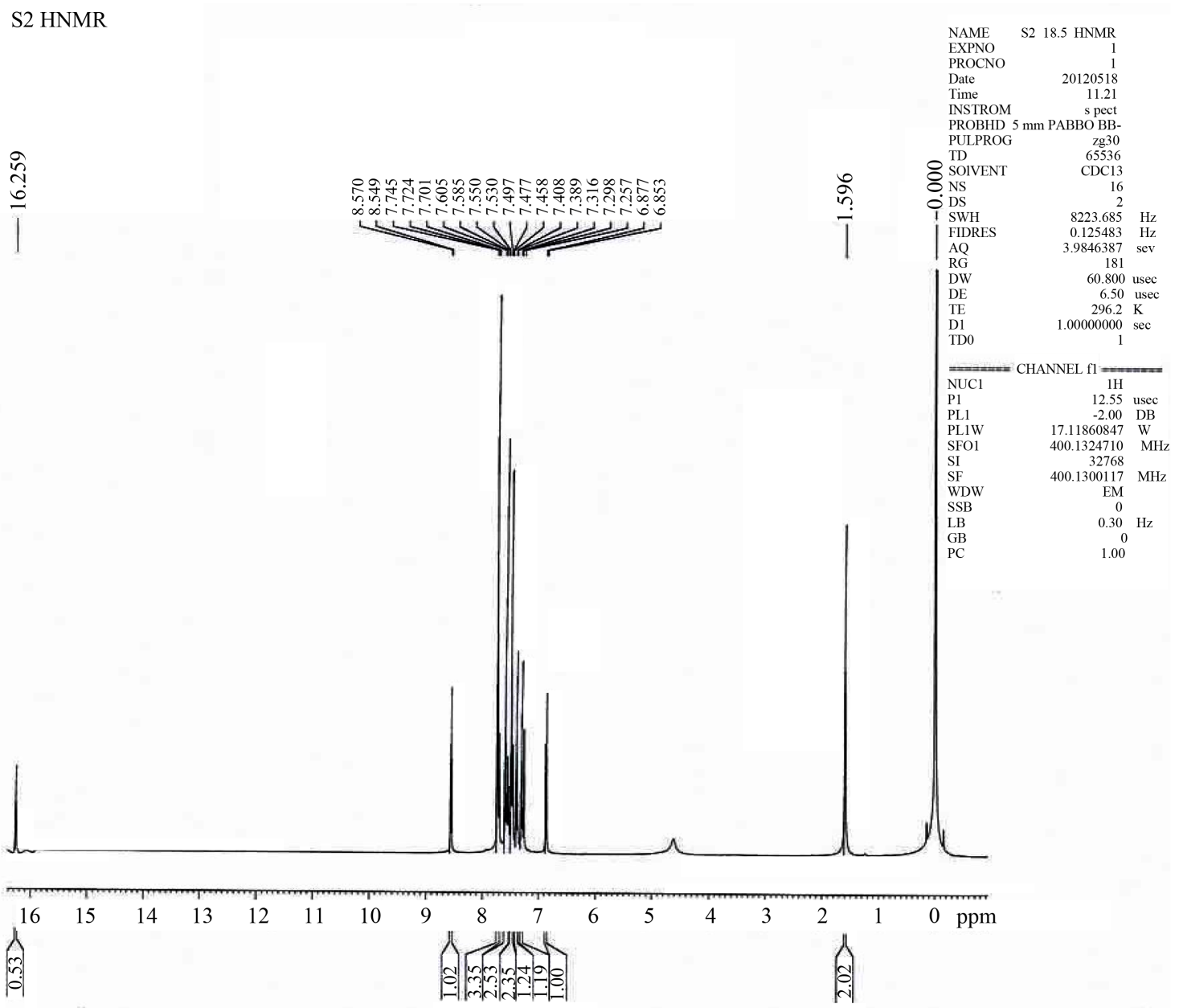

Figure 5. NMR spectrum of recrystalized PAN concentration $10^{-4} \mathrm{~mole} \cdot \mathrm{dm}^{-3}$. 
solvent. Peak at 16.259 is due to impurity present. The peak at 5 is due to hydrogen bonding which may vary according to the concentration. The hydrogen present in carbon lying near to $(-\mathrm{N}=\mathrm{N}-)$ is having high value 7.93 due to the presence of $(-\mathrm{N}=\mathrm{N}-)$ group adjacent to it. The following data were obtained from the NMR spectrum of the recrystalized sample of PAN having concentration $10^{-4}$ mole $\cdot \mathrm{dm}^{-3}$.

Data obtained from Figure 5 NMR spectrum of PAN:

1) The peak at 7.93 will split into two because of presence of one neighboring Hydrogen atom.

2) The peak at 7.46 splits into three because of presence of two neighboring Hydrogen atom.

3) The peak at 5 does not split because of absence of neighboring Hydrogen atom.

4) The peak at 7.17 splits into two because of presence of one neighboring Hydrogen atom.

5) The peak at 7.82 splits into three due to presence of two neighboring Hydrogen atom.

6) The peak at 7.63 splits into two due to the presence of one neighboring Hydrogen atom.

7) The peak at 7.30 splits into three due to the presence of two neighboring atom.

The peak at 7.53 splits into two due to the presence of one neighboring atom.

Based on the above observations, the structural elucidation of phenyl azo $\beta$-naphthol (PAN), which was synthesised in our laboratory, having concentration $10^{-4}$ mole $\cdot \mathrm{dm}^{-3}$ as shown below.

\section{ChemNMR H-1 Estimation}

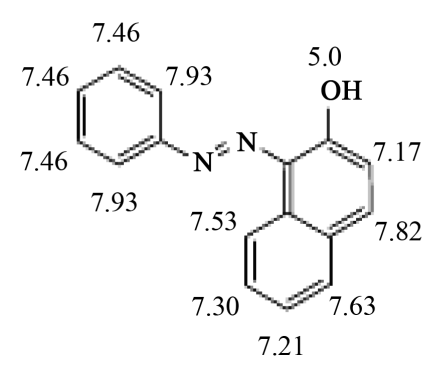

\section{Conclusions}

The purpose of the study is to work out the most efficient and cost effective method for decolourization and degradation of azo dye, viz, phenyl azo $\beta$-naphthol (PAN). The present work described the use of two sources of photo dissociation such as sunlight of $495 \mathrm{~nm}$ and uv-light of $254 \mathrm{~nm}$ wavelength simultaneously

On observation of the effect of $\mathrm{Fe}^{2+}$ concentration in Fenton reagent using both sources at low $\mathrm{pH} 2$ by fixing the concentration of other components in it, the decolorization efficiency increases dramatically. However, the inhibitory effect at relatively high concentration of $\mathrm{Fe}^{2+}$ ion above $\left(3 \times 10^{-4} \mathrm{~mol} \cdot \mathrm{dm}^{-3}\right)$ at near neutral $\mathrm{pH} 6$ could be explained by an observation that $\mathrm{Fe}^{2+}$ ion are the dominant ${ }^{\bullet} \mathrm{OH}$ radical scavenger.

Thus, solar assisted photo irradiation and uv-light source at moderately low concentration of $\mathrm{Fe}^{2+}$ ion for performing advanced oxidation process (Fenton reaction) would be cost-effective, fulfilling energy saver management and at the same time environmental friendly too.

\section{Acknowledgements}

I acknowledge Prof. Dr. Charuvelil Aravindakumar, Dean \& Hon. Director, School of Environmental Sciences, offered collaborative works at Inter University Instrumentation Centre (IUIC), Mahatma Gandhi University, Kerala, India. I would like to extend acknowledgement to my parental institution (NSS Hindu College, Changanassery, Kerala, India) and the research centre (Post Graduate and Research Department of Chemistry, SB College, Changanassery, Kerala, India).

\section{References}

[1] IUPAC (1997) Compendium of Chemical Terminology. 2nd Edition, (the “Gold Book”). Online Corrected Version (2009) “Azo Compounds”. UPAC Secretariat, Research Triangle Park.

[2] Clarke, H.T. and Kirner, W.R. (1941) Methyl Red. Organic Syntheses, 1, 374.

[3] O’Neill, C., Lopez, A., Esteves, S., Hawkes, F.R., Hawkes, D.L. and Wilcox, S. (2000) Feb, Azo-Dye Degradation in 
an Anaerobic-Aerobic Treatment System Operating on Simulated Textile Effluent. Applied Microbiology and Biotechnology, 53, 249-254. http://dx.doi.org/10.1007/s002530050016

[4] SPCC Guidance for Regional Inspectors, USA (2013) 1-73.

[5] Türgay, O., Ersöz, G., Atalay, S., Forss, J. and Welander, U. (2011) The Treatment of Azo Dyes Found in Textile Industry Wastewater by Anaerobic Biological Method and Chemical Oxidation. Separation and Purification Technology, 79, 26-33. http://dx.doi.org/10.1016/j.seppur.2011.03.007

[6] Puvaneswari, N., Muthukrishnan, J. and Gunasekaran, P. (2006) Toxicity Assessment and Microbial Degradation of Azo Dyes. Indian Journal of Experimental Biology, 44, 618-626.

[7] Zhao, X.T., Dong, Y.C., Cheng, B.W. and Kang, W.M. (2013) Removal of Textile Dyes from Aqueous Solution by Heterogeneous Photo-Fenton Reaction Using Modified PAN Nanofiber-Fe Complex as Catalyst. International Journal of Photoenergy, 2013, Article ID: 820165. http://dx.doi.org/10.1155/2013/820165

[8] Hua, L., Ma, H. and Zhang, L. (2013) Degradation Process Analysis of the Azo Dyes by Catalytic Wet Air Oxidation with Catalyst $\mathrm{CuO} / \gamma-\mathrm{Al}_{2} \mathrm{O}_{3}$. Chemosphere, 9, 143-149. http://dx.doi.org/10.1016/j.chemosphere.2012.06.018

[9] Chequer F.M.D., Dorta, D.J. and de Oliveira, D.P. (2011) Azo Dyes and Their Metabolites: Does the Discharge of the Azo Dye into Water Bodies Represent Human and Ecological Risks? In: Hauser, P.J., Ed., Advances in Treating Textile Effluent, InTech, $162 \mathrm{p}$.

[10] Kavitha, V. and Palanivelu, K. (2004) The Role of Ferrous Ion in Fenton and Photo-Fenton Processes for the Degradation of Phenol. Chemosphere, 55, 1235-1243. http://dx.doi.org/10.1016/j.chemosphere.2003.12.022

[11] Selvam, K., Muruganandham, M. and Swaminathan, M. (2005) Enhanced Heterogeneous Ferrioxalate Photo-Fenton Degradation of Reactive Orange 4 by Solar Light. Solar Energy Materials and Solar Cells, 89, 61-74. http://dx.doi.org/10.1016/j.solmat.2005.01.002

[12] Munter, R. (2001) Advanced Oxidation Processes-Current Status and Prospects. Proceedings of the Estonian Academy of Sciences, Chemistry, 50, 59-80.

[13] Chequer, F.M.D., Dorta, D.J. and de Oliveira, D.P. (2011) Azo Dyes and Their Metabolites: Does the Discharge of the Azo Dye into Water Bodies Represent Human and Ecological Risks? In: Hauser, P.J., Ed., Advances in Treating Textile Effluent, InTech, Morn Hill, 1-23.

[14] Pandey, A., Singh, P. and Iyengar, L. (2007) Review: Bacterial Decolorization and Degradation of Azo Dyes. International Biodeterioration \& Biodegradation, 59, 73-84.

[15] Saratale, R.G., Saratale, G.D., Chang, J.S. and Govindwar, S.P. (2011) Bacterial Decolorization and Degradation of Azo Dyes: A Review. Journal of the Taiwan Institute of Chemical Engineers, 42, 138-157.

[16] Anliker, R. (1977) Color Chemistry and the Environment. Ecotoxicology and Environmental Safety, 1, 211-237. http://dx.doi.org/10.1016/0147-6513(77)90037-9

[17] Anliker, R. (1979) Ecotoxicology of Dyestuffs-A Joint Effort by Industry. Ecotoxicology and Environmental Safety, 3, 59-74. http://dx.doi.org/10.1016/0147-6513(79)90060-5

[18] Robinson, T., McMullan, G., Marchant, R. and Nigam, P. (2001) Remediation of Dyes in Textile Effluent: A Critical Review on Current Treatment Technologies with a Proposed Alternative. Bioresource Technology, 77, 247-255.

[19] Shore, J. (1996) Advances in Direct Dyes. Indian Journal of Fibers and Textile Research, 21, 1-29.

[20] Golka, K., Kopps, S. and Myslak, Z.W. (2004) Carcinogenicity of Azo Colorants: Influence of Solubility and Bioavailability—A Review. Toxicology Letters, 151, 203-210.

[21] Nogueira, R.F.P. and Guimaraes, J.R. (2000) Photodegradation of Dichloroacetic Acid and 2,4-Dichlorophenol by Ferrioxalate/ $\mathrm{H}_{2} \mathrm{O}_{2}$ System. Water Research, 34, 895-901. http://dx.doi.org/10.1016/S0043-1354(99)00193-1

[22] Kavitha, V. and Palanivelu, K. (2004) The Role of Ferrous Ion in Fenton and Photo-Fenton Processes for the Degradation of Phenol. Chemosphere, 55, 1235-1243. http://dx.doi.org/10.1016/j.chemosphere.2003.12.022

[23] Tang, W.Z. and Huang, C.P. (1996) 2,4-Dichlorophenol Oxidation Kinetics by Fenton’s Reagent. Environmental Technology, 17, 1371-1378. http://dx.doi.org/10.1080/09593330.1996.9618465

[24] Kwon, B.G., Lee, D.S., Kang, N. and Yoon, J. (1999) Characteristics of p-Chlorophenol Oxidation by Fenton’s Reagent. Water Research, 33, 2110-2118. http://dx.doi.org/10.1016/S0043-1354(98)00428-X

[25] Kremer, M.L. (2003) The Fenton Reaction. Dependence of the Rate on pH. The Journal of Physical Chemistry A, 107, 1734-1741. http://dx.doi.org/10.1021/jp020654p

[26] Kang, Y.W. and Hwang, K.Y. (2000) Effects of Reaction Conditions on the Oxidation Efficiency in the Fenton Process. Water Research, 34, 2786-2790. http://dx.doi.org/10.1016/S0043-1354(99)00388-7

[27] Barbusiński, K. and Majewski, J. (2003) Discoloration of Azo Dye Acid Red 18 by Fenton Reagent in the Presence of Iron Powder. Polish Journal of Environmental Studies, 12, 151-155. 
[28] Bishop, D.F., Stern, G., Fleischman, M. and Marshall, L.S. (1968) Hydrogen Peroxide Catalytic Oxidation of Refractory Organics in Municipal Waste Water. Indian Engineering Chemistry Processing Design and Development, 7, 110-117. http://dx.doi.org/10.1016/S0043-1354(99)00388-7 
Scientific Research Publishing (SCIRP) is one of the largest Open Access journal publishers. It is currently publishing more than 200 open access, online, peer-reviewed journals covering a wide range of academic disciplines. SCIRP serves the worldwide academic communities and contributes to the progress and application of science with its publication.

Other selected journals from SCIRP are listed as below. Submit your manuscript to us via either submit@scirp.org or Online Submission Portal.
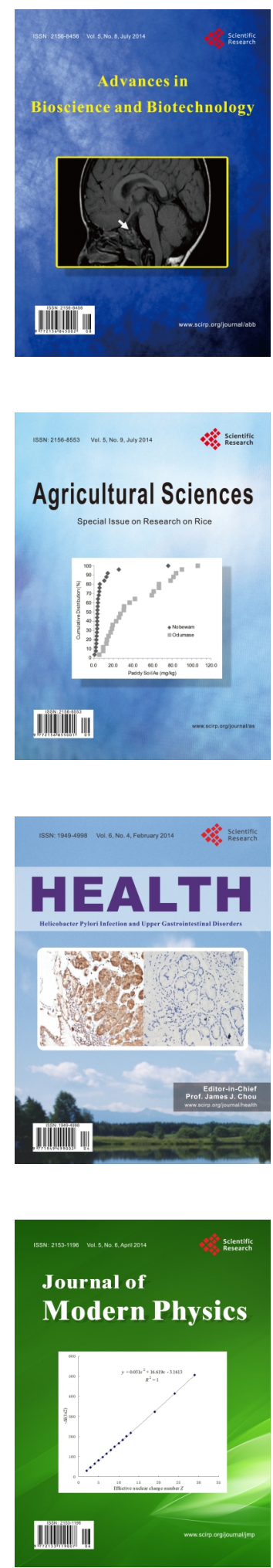
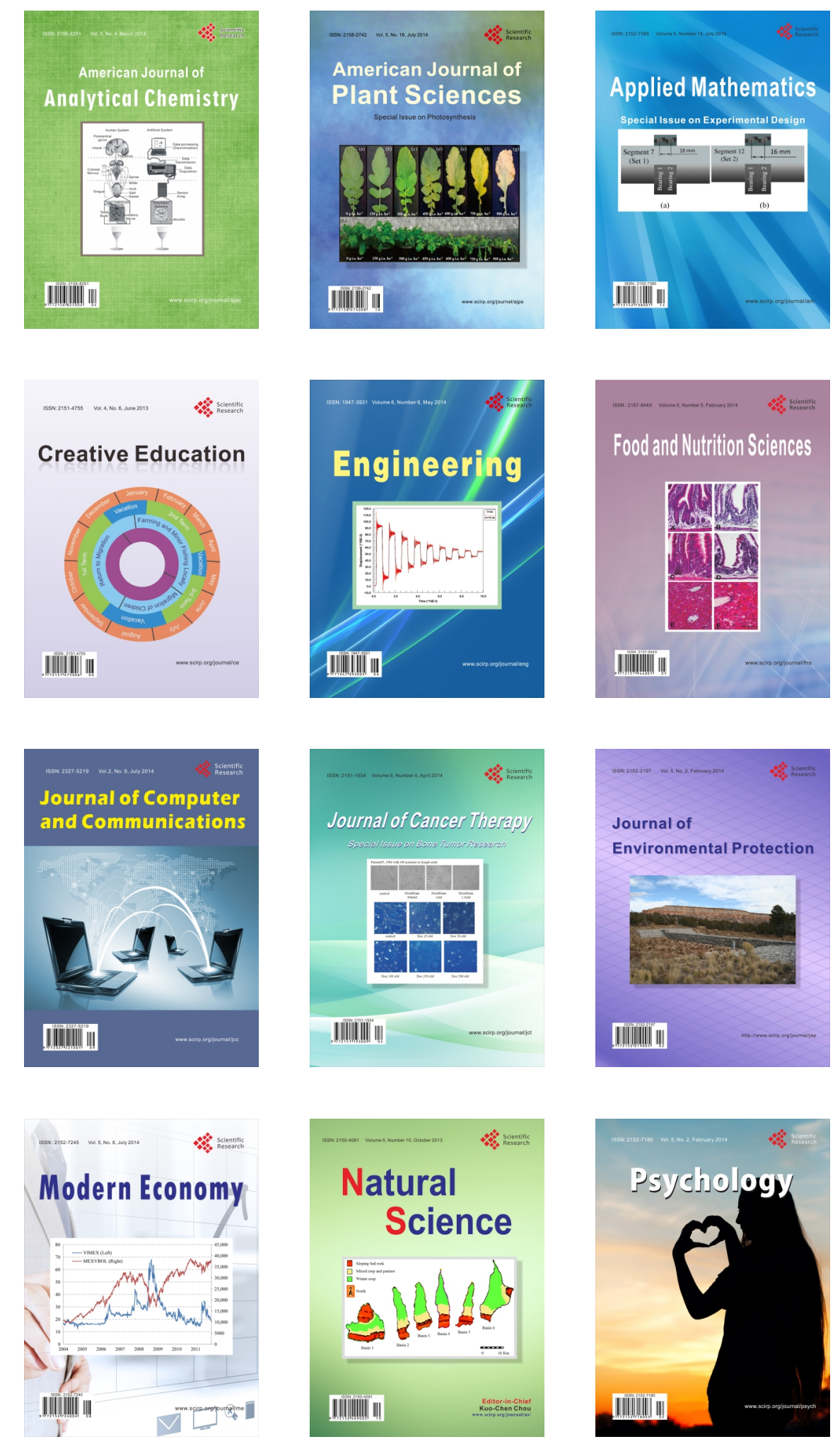